Published in final edited form as:

Ann Allergy Asthma Immunol. 2019 April ; 122(4): 393-400.e2. doi:10.1016/j.anai.2019.01.001.

\title{
IgE Testing Can Predict Food Allergy Status in Patients with Moderate-Severe Atopic Dermatitis
}

\author{
Pamela A. Frischmeyer-Guerrerio, MD, PhDa ${ }^{a}$ Marjohn Rasooly, MSNa, Wenjuan Gu, MS $^{b}$, \\ Samara Levin, BS ${ }^{a}$, Rekha D. Jhamnani, MDa, Joshua D. Milner, MD ${ }^{\mathrm{a}}$, Kelly Stone, MD \\ $\mathrm{PhD}^{\mathrm{a}}$, Anthony L. Guerrerio, MD $\mathbf{P h D}^{\mathrm{C}}$, Joseph Jones, $\mathbf{M S}^{\mathrm{d}}$, Magnus P. Borres, $\mathbf{M D}^{\mathrm{e}}$, and \\ Erica Brittain, $\mathbf{P h D}^{\mathrm{f}}$ \\ aLaboratory of Allergic Diseases, NIAID, NIH, Bethesda, MD \\ ${ }^{b}$ Clinical Research Directorate/Clinical Monitoring Research Program, Leidos Biomedical \\ Research, Inc., NCl Campus, Frederick, MD \\ 'Department of Pediatrics, Johns Hopkins School of Medicine, Baltimore, MD \\ IImmunoDiagnostics Branch, Thermo Fisher Scientific, Phadia US Inc., Portage, MI \\ eDepartment of Maternal and Child Health, Uppsala University, Uppsala, Sweden \\ 'Biostatistics Research Branch, DCR, NIH, Bethesda, MD
}

\section{Keywords}

Atopic dermatitis; component testing; eczema; food allergy; IgE

\section{Introduction}

\begin{abstract}
Atopic dermatitis (AD) is the most common chronic inflammatory disease of the skin in pediatric populations, affecting up to $20 \%$ of children in industrialized countries. ${ }^{1-4} \mathrm{AD}$ is frequently associated with other atopic diseases. ${ }^{5,}{ }^{6} \mathrm{Up}$ to two-thirds of AD patients are sensitized to food antigens, and 15-40\% have clinical food allergy. ${ }^{7-11}$ Children with severe and persistent $\mathrm{AD}$ are at highest risk for having coexistent food allergy. $5,12,13$

Food-specific IgE (sIgE) testing has been reported to have limited diagnostic utility in AD patients. ${ }^{11,14,15}$ This has been attributed to the high levels of total serum IgE common in these patients, which can lead to false positive testing, detecting sensitizations to foods not
\end{abstract}

\footnotetext{
Address correspondence to: Pamela A. Guerrerio, MD PhD, Building 10, Room 11N240B, MSC 1889, 10 Center Drive, Bethesda, MD 20892, Phone: (301) 402-9782, Fax: (301) 480-4507, pamela.guerrerio@ nih.gov.

Publisher's Disclaimer: This is a PDF file of an unedited manuscript that has been accepted for publication. As a service to our customers we are providing this early version of the manuscript. The manuscript will undergo copyediting, typesetting, and review of the resulting proof before it is published in its final citable form. Please note that during the production process errors may be discovered which could affect the content, and all legal disclaimers that apply to the journal pertain.

Conflict of Interest

M.P. Borres and J. Jones are employees of Thermo Fisher Scientific (Uppsala, Sweden). P.A. Frischmeyer-Guerrerio has received material from Thermo Fisher to perform the IgE analyses in this project. The other authors have indicated they have no potential conflicts of interest to disclose.
} 
associated with symptoms upon ingestion. This frequently leads to unnecessary food avoidance, which can not only have adverse nutritional consequences but also a profound negative impact on quality of life. Decision points of sIgE levels for some of the most common food allergens, including milk ( $\left.32 \mathrm{kU}_{\mathrm{A}} / \mathrm{L}\right)$, egg $\left(7 \mathrm{kU} \mathrm{A}_{\mathrm{A}} / \mathrm{L}\right)$, and peanut $\left(15 \mathrm{kU}_{\mathrm{A}} / \mathrm{L}\right)$, have been defined where there is a greater than $95 \%$ probability of reacting to the food during an oral food challenge (OFC). ${ }^{16-19}$ However, in a cohort of 125 AD patients, no patient with a sIgE level below these $95 \%$ positive predictive values (PPV) for milk, egg, or peanut failed an OFC, suggesting that sIgE testing may not be reliable in predicting food allergy in $\mathrm{AD}$ populations. ${ }^{15}$

Given these challenges, there is great interest in identifying strategies that will improve the accuracy of food allergy diagnosis among patients with AD. While OFCs are the gold standard for establishing a diagnosis, these procedures are time-consuming, require specially trained personnel, and carry an inherent risk of inducing a severe allergic reaction. Some but not all studies have suggested that the ratio of $\operatorname{sgE}$ to total IgE is a better predictor of OFC outcomes than sIgE levels alone. ${ }^{20-22}$ Other studies have found that component testing, where $\mathrm{IgE}$ to individual allergens is measured, may be more accurate in diagnosing food allergy than conventional IgE testing to natural extracts, which consist of a complex mixture of proteins. ${ }^{23-38}$ The utility of component testing has been best studied with peanut, where IgE to Ara h2 has been shown to be the single best predictor of peanut allergy. ${ }^{23-28} \mathrm{High}$ IgE levels to Gal d1 (ovomucoid) and Bos d8 (casein) have also been associated with more persistent allergy and reactivity to both heated and concentrated forms of egg and milk, respectively. ${ }^{29-38}$

In this study, we sought to examine the utility of specific- and component-IgE testing in predicting food allergy among children with moderate-severe AD.

\section{Methods}

\section{Study Population}

Subjects 2-20 years of age with moderate to severe AD were enrolled in the Natural History of Atopic Dermatitis Protocol 10-I-0148 at the National Institutes of Health. This study was approved by the institutional review board and subjects underwent informed consent and assent, where applicable. Subjects with AD secondary to a known genetic disorder were excluded from the study.

The severity of atopic dermatitis index score (SCORAD) was assessed on all subjects. The presence of food allergy to the five most common food allergens was determined by a detailed clinical history and review of clinical records. To be diagnosed with food allergy, subjects had to have objective symptoms (based on the PRACTALL guidelines ${ }^{39}$ ) of a hypersensitivity reaction to the food (e.g. hives with erythema and/or angioedema, persistent cough, wheezing, vomiting, hypotension) within approximately 30-60 minutes of eating the food along with positive sIgE testing. Subjects who tolerated baked milk and/or egg but clearly reacted to less extensively heated forms of the food were classified as allergic ( $n=3$ for milk and $\mathrm{n}=2$ for egg). Subjects were classified as nonallergic to the food if they were eating the food on a regular basis in their diet with no overt symptoms. Subjects whose 
reactivity to a food was unclear because they had never been exposed to the food and were avoiding it due to positive testing ( $\mathrm{n}=4$ for milk, $\mathrm{n}=4$ for egg, $\mathrm{n}=3$ for soy, $\mathrm{n}=0$ for wheat, and $\mathrm{n}=25$ for peanut) were excluded from the analysis for that food.

\section{Serologic Measurements}

Serum from each subject was initially screened for sensitization to the most common food allergens with the $\mathrm{fx} 5$, a multiallergen ImmunoCAP assay that detects IgE antibodies to a mix of egg white, milk, wheat, peanut, and soybean (Thermo Fisher, Uppsala, Sweden). If the fx5 test was positive, sIgE testing was performed for cow's milk, egg white, soybean, wheat, and peanut. Reflex ImmunoCAP component testing was then performed for each food where the $\mathrm{sIgE}$ test was positive $\left(>0.10 \mathrm{kU}_{\mathrm{A}} / \mathrm{L}\right)$. Total serum IgE was measured on all subjects by ImmunoCAP. All samples where the IgE level was above the limit of detection $\left(>100 \mathrm{kU}_{\mathrm{A}} / \mathrm{L}\right.$ for $\mathrm{sIgE}$ and component IgE; $>5000 \mathrm{kU} / \mathrm{L}$ for total $\mathrm{IgE}$ ) were diluted and rerun to obtain more precise measurements.

\section{Statistical Methods}

Wilcoxon rank sum tests were used to compare SCORAD, IgE, sIgE, component IgE, and IgE ratios between allergic and non-allergic subjects for each food; box plots illustrate these relationships graphically. The corresponding Mann-Whitney (MW) parameters were estimated to reflect the strength and direction of the relationships. The MW estimate represents the probability that a random allergic subject has a higher value on the predictor than a random non-allergic subject. MW also equals the area under the curve (AUC) of the receiver operating curve (ROC) of sensitivity against 1 -specificity when $\mathrm{MW}>0.5$, and 1$\mathrm{MW}=\mathrm{AUC}$ when $\mathrm{MW}<0.5$.

Logistic regression was used to estimate thresholds of each univariate predictor associated with $50 \%$ probability of allergy. Bootstrap $95 \%$ confidence intervals based on this $50 \%$ threshold were computed. The negative predictive value (NPV) and positive predictive value (PPV) were computed using a model-based approach. The NPV is the mean logistic regression estimated probability of not having allergy across all individuals with values less than or equal to the reference value. Model based estimates of PPV were computed likewise. A special approach was used for peanut NPV and PPV, because of the substantial missingness on peanut allergy status. While the employed logistic estimates are derived from subjects with known allergy status to peanut, the NPV and PPV computations, which use these logistic estimates, included subjects with unknown peanut allergy status to reflect the distribution of predictor values in the full cohort.

Multivariate predictors were considered using classification trees to predict milk, egg, and peanut allergy. Before examining the data, we pre-specified an algorithm ${ }^{40}$ to determine an optimum tree considering all $\mathrm{IgE}$ measures relevant to the respective food allergy including ratios. The algorithm applied cross-validation to find the misclassification rate as a function of the number of nodes. Then the optimal subtree with the previously determined optimal number of nodes was selected. For those foods where this algorithm produced a split on only a single variable, the algorithm was modified with a 2:1 misclassification cost function, and 
where that failed, an ad hoc multivariate tree-like rule was postulated from direct examination of the data. Scatterplots illustrate the tree decision rules.

Tests were two-sided and p-values less than 0.05 were considered statistically significant. No adjustments were made for multiple comparisons, and while it is always appropriate to interpret such results cautiously, the concern about multiplicity is relatively muted in this context, given the large number of highly significant results.

\section{Results}

\section{Prevalence of Food Sensitization and Allergy}

78 subjects ( $65 \%$ male) with a median age of 10.7 years were enrolled (Table 1). $43.6 \%$ of the subjects were Caucasian, 24.4\% Asian, 14.1\% multiracial, 12.8\% African American, 1.3\% American Indian/Alaska native, $1.3 \%$ Indian, and 1.3\% unknown. Four percent were Hispanic. The median total SCORAD was 45 and median total IgE 5338 kU/L (Table 1).

Ninety-one percent of subjects were sensitized $\left(\operatorname{sIgE}>0.10 \mathrm{kU}_{\mathrm{A}} / \mathrm{L}\right)$ to at least one of the five most common food allergens ( $91 \%$ to milk, $90 \%$ to egg, $88 \%$ to peanut, $91 \%$ to wheat, and $87 \%$ to soy); $86 \%$ were sensitized to all 5 foods. We next assessed clinical reactivity, and $51 \%$ were allergic to at least one of the foods, including $26 \%$ to cow's milk, $27 \%$ to egg, $24 \%$ to peanut, $5 \%$ to wheat, and $6 \%$ to soy. Except for wheat, these percentages may be underestimates as some subjects had never been exposed to the food and were therefore excluded from the analysis for that food ( 4 subjects for milk, 4 for egg, 25 for peanut, 0 for wheat, 3 for soy). Of the 78 subjects, $22 \%$ reported allergic reactivity to only one of the five foods, and $23 \%, 5.1 \%$, and $1.3 \%$ to two, three, and four foods, respectively. There was no difference in age, gender, ethnicity, race, or coexistent allergic disease between those allergic to at least one food and those nonallergic to all five foods (Table 1). Subjects who had egg allergy were more likely to be allergic to other foods, including milk ( $\mathrm{p}=0.0042)$, peanut $(\mathrm{p}=0.0005)$, and wheat $(\mathrm{p}=0.0205$; Supplemental Table 1). Of the 21 subjects allergic to egg, all but one had an allergy to another food.

The severity of AD, as assessed by SCORAD, was not different between subjects allergic versus tolerant to any of the five foods (Supplemental Fig 1; Tables 2-4; Supplemental Tables 2,3) or between those allergic to at least one of the five foods and those tolerant to all 5 foods (Table 1). Although median total serum IgE levels were higher among subjects allergic versus nonallergic to each of the five foods, the difference did not reach statistical significance, except for peanut where levels were higher in those with peanut allergy (Supplemental Fig 1; Tables 2-4; Supplemental Tables 2, 3). Total IgE was also increased in subjects allergic to at least one of the foods compared to those tolerant to all five foods (Table 1).

\section{Ability of food- and component-specific IgE levels to discriminate allergic status}

As shown in Tables 2-4, Supplemental Figs 2-6, and Supplemental Tables 2 and 3, levels of sIgE to milk, egg, peanut, and wheat (but not soy) were higher among AD subjects allergic to the food compared to those who were tolerant, and these differences were statistically 
significant. Component-specific IgEs for these foods also discriminated allergic status (except for soy).

The highest levels of component-specific IgE in milk allergic subjects were directed against Bos d8, although all milk component IgEs were higher in milk allergic $(n=20)$ than milk tolerant ( $\mathrm{n}=54)$ subjects (Supplemental Fig 2, Table 2). Egg-allergic subjects $(\mathrm{n}=21)$ had high amounts of Gal d1 and Gal d2 IgE but not Gal d3 IgE. On the other hand, egg-tolerant subjects $(n=53)$ generally had low IgE to all 3 egg components, and levels were significantly below those in the allergic group for Gal d1 and Gal d2 (Supplemental Fig 3, Table 3). While levels of IgE to peanut and its components Ara h1, Ara h2, and Ara h3 were higher among peanut allergic $(n=19)$ versus nonallergic $(n=34)$ subjects, the difference was greatest for Ara $\mathrm{h} 2$, and this component dominated the IgE response to peanut in the allergic group (Supplemental Fig 4, Table 4). On the other hand, IgE to Ara h8 and Ara h9 were generally low, and no significant differences were noted based on allergic status to peanut.

The frequency of allergy to wheat and soy in this cohort was relatively low; however, there was a trend $(\mathrm{p}=0.0543)$ towards higher levels of Tri a19 $\operatorname{IgE}$ in the wheat allergic $(n=4)$ compared to nonallergic ( $\mathrm{n}=74)$ group, while levels of Tri a14 IgE were not different (Supplemental Fig 5, Supplemental Table 2). No significant differences in either soy IgE or soy component (Gly m4, Gly m5, Gly m6, Gly m8) IgEs were detected between subjects allergic $(\mathrm{n}=5)$ and tolerant $(\mathrm{n}=70)$ to soy (Supplemental Fig 6, Supplemental Table 3).

\section{Utility of IgE ratios in determining food allergy status}

To compare the utility of specific or component-IgE values alone or as a ratio to total serum IgE or sIgE, respectively, we calculated Mann-Whitney parameters (MW). The MW describes the probability that a random allergic subject has a higher value than a random nonallergic subject. Therefore, MW values greater than 0.5 indicate a positive association with allergy, those less than 0.5 a positive association with tolerance, and those equal to 0.5 suggest no relationship between the value and allergic status.

With regard to milk, the MW for milk, Bos d4, Bos d5, and Bos d8 IgE all approached one, indicating higher levels in milk allergic versus tolerant patients with little overlap in IgE levels between the groups ( $<<0.00001$ for all; Supplemental Fig 2; Table 2). The MW for Bos d6 $\operatorname{IgE}(0.70 ; \mathrm{p}=0.0104)$ also indicated a positive, albeit weaker, association with allergy. The ratio of component IgE to milk IgE revealed a MW parameter of 0.67 for Bos $\mathrm{d} 8(\mathrm{p}=0.0252), 0.25$ for Bos $\mathrm{d} 5$ and Bos d6 ( $\mathrm{p}=0.0011$ for both), and 0.36 for Bos $\mathrm{d} 4$ $(\mathrm{p}=0.0726$; Supplemental Fig 2; Table 2) suggesting that a greater proportion of milk $\operatorname{IgE}$ is directed against Bos $\mathrm{d} 8$ in those subjects with milk allergy, and against Bos $\mathrm{d} 4, \mathrm{~d} 5$ and $\mathrm{d} 6$ in those who are milk tolerant.

The MW for egg (0.86), Gal d1 (0.88), and and Gal d2 (0.86) IgE indicated higher levels in egg allergic subjects ( $<<0.0001$ for all), while the MW for Gal d3 (0.63) IgE was not statistically significant (Supplemental Fig 3; Table 3). The MW parameter for the ratio of Gal d1 to egg $\operatorname{IgE}(0.63 ; p=0.0872)$ suggested a positive association with egg allergy, while the ratio of $\mathrm{Gal} d 3$ to egg $\operatorname{IgE}(0.35 ; \mathrm{p}=0.0500)$ suggested a positive association with 
tolerance. The MW for the ratio of Gal d2/egg IgE (0.54) was not statistically significant (Supplemental Fig 3; Table 3).

The highest MW parameter for peanut was for Ara h2 IgE (MW 0.97, p<0.00001), indicating a strong association between high Ara $\mathrm{h} 2 \mathrm{IgE}$ and the presence of peanut allergy (Supplemental Fig 4; Table 4). MW estimates for peanut (MW 0.92, p<0.00001), Ara h1 (MW 0.89, p<0.00001), and Ara h3 (MW 0.89, p<0.00001) IgE also indicated an association with peanut allergy, while the MW parameters for Ara h8 and Ara h9 IgE alone did not indicate a significant relationship. The MW for the ratio of Ara h2 IgE/peanut IgE (MW 0.86; $\mathrm{p}=0.00004$ ) or Arah1/peanut IgE (MW 0.70; $\mathrm{p}=0.0279$ ) also demonstrated a strong association with peanut allergy, while the ratio of Ara $\mathrm{h} 8 \mathrm{IgE} /$ peanut IgE indicated an association with tolerance (MW 0.30; $\mathrm{p}=0.0243$ ). The ratio of Ara $\mathrm{h} 3$ or Ara $\mathrm{h} 9 \mathrm{IgE}$ to peanut IgE was not significant. These data suggest that the dominant IgE response to peanut is against Ara $\mathrm{h} 2$ and Ara $\mathrm{h} 1$ in allergic subjects and against Ara $\mathrm{h} 8$ in tolerant subjects.

Regarding wheat, the MW for Tri a19 IgE (0.78) suggested higher levels in those with wheat allergy $(\mathrm{p}=0.0543)$ and reached significance when the ratio of Tri a19/total IgE was considered (MW 0.83; p=0.0236; Supplemental Fig 5; Supplemental Table 2). None of the MW parameters for soy indicated statistically significant relationships between IgE levels and allergy status (Supplemental Fig 6; Supplemental Table 3).

Calculating the ratio of sIgE, or each of the component IgEs, to total IgE minimally changed the MW compared to each of these parameters alone for all foods tested (Tables 2-4, Supplemental Figs 2-6, and Supplemental Tables 2 and 3).

The pattern of IgE reactivity to milk, egg, and peanut, as well as the components for each of these foods in relation to sIgE, for individual subjects is shown in Supplemental Figs 7-9.

\section{Identification of diagnostic thresholds}

Clinically, oral food challenges are generally recommended when a child has at least a 50\% chance of passing the challenge. We therefore calculated sIgE levels that estimate a 50\% likelihood of tolerating milk, egg, and peanut in our cohort. For milk, this decision point was $42.8 \mathrm{kU}_{\mathrm{A}} / \mathrm{L}$, which had a sensitivity of 0.850 , specificity of 0.963 , PPV of 0.835 and NPV of 0.932 (Table 5). For egg, the threshold level was $28.0 \mathrm{kU}_{\mathrm{A}} / \mathrm{L}$, which had a sensitivity of 0.619 , specificity of 0.905 , PPV of 0.709 and NPV of 0.847 (Table 6). For peanut, Ara h2 $\operatorname{IgE}$ was a better predictor of peanut allergy than peanut $\operatorname{IgE}$ levels. The decision point for Ara h2 IgE was $10.9 \mathrm{kU}_{\mathrm{A}} / \mathrm{L}$, which had a sensitivity of 0.842 , specificity of 0.912 , PPV of 0.859 and NPV of 0.924 . A peanut $\mathrm{IgE}$ level of $36.4 \mathrm{kU}_{\mathrm{A}} / \mathrm{L}$ had a sensitivity of 0.737 , specificity of 0.941 , PPV of 0.830 and NPV of 0.846 (Table 7).

Many of the subjects in our cohort had $\operatorname{sgE}$ values above $100 \mathrm{kU}_{\mathrm{A}} / \mathrm{L}$, the upper limit of quantification for the ImmunoCAP. We therefore calculated the predictive probabilities for allergy to milk, egg, and peanut at a sIgE level of $100 \mathrm{kU}_{\mathrm{A}} / \mathrm{L}$ or above. We also determined IgE decision points that maximized sensitivity and specificity for predicting allergy to these foods. (Tables 5-7). 
Logistic curves demonstrating the probability of allergy at a given sIgE level are shown in Supplemental Fig 10.

\section{Decision trees for milk, egg, and peanut}

As a proof of concept, we next asked whether the specific and component IgE tests used in a step-wise fashion could improve their predictive capacity, using a pre-specified algorithm for forming classification trees. The algorithm produced a tree for milk suggesting that milk $\operatorname{IgE}$ testing followed by IgE testing to Bos $\mathrm{d} 8$ may have added utility in predicting milk allergy in this cohort (Fig 1). 51/52 subjects with milk $\operatorname{IgE}<26.1 \mathrm{kU}_{\mathrm{A}} / \mathrm{L}$ were not allergic to milk. Among those with milk $\operatorname{IgE}>26.1 \mathrm{kU} \mathrm{A}_{\mathrm{A}} / \mathrm{L}$, all 17 whose ratio of Bos d8 IgE/milk-specific $\operatorname{IgE}$ was greater than 0.5 were allergic to milk, compared to only $2 / 5$ whose ratio was less than 0.5 .

When the algorithm was refined such that misclassifying non-allergy was considered twice as bad as misclassifying allergy, this resulted in a two-step classification for egg (Fig 1). Among those with egg $\operatorname{IgE}<16 \mathrm{kU}_{\mathrm{A}} / \mathrm{L}, 6$ of 54 had allergy to egg. However, among those with egg $\operatorname{IgE} \geq 16 \mathrm{kU}_{\mathrm{A}} / \mathrm{L}$ : if the ratio of Gal d1 $\operatorname{IgE} /$ egg $\operatorname{IgE}<0.14 \mathrm{kU}_{\mathrm{A}} / \mathrm{L}$, one in 4 had allergy; if the ratio was $>0.14 \mathrm{kU}_{\mathrm{A}} / \mathrm{L}, 14$ out of 16 had allergy.

While the pre-specified algorithm did not produce multiple variable thresholds for peanut, examination of the data suggests an exploratory tree. Among the 33 subjects with Ara h2 $\operatorname{IgE}<10 \mathrm{kU}_{\mathrm{A}} / \mathrm{L}$, only 2 have allergy. Among the 6 with Ara $\mathrm{h} 2 \mathrm{IgE}>10 \mathrm{kU} \mathrm{A}_{\mathrm{A}} / \mathrm{L}$ but with Ara h8 IgE/peanut IgE $>0.09$, half have allergy. And, among the 14 with Ara h2 IgE $>10 \mathrm{kU} \mathrm{A}_{\mathrm{A}} / \mathrm{L}$ but Ara h8 IgE/peanut IgE $<0.09$, all had allergy (Fig 1).

\section{Discussion}

The high rate of IgE-mediated food allergy in $\mathrm{AD}$ patients necessitates diagnostic strategies that can distinguish asymptomatic sensitization from clinical food allergy ${ }^{5-11}$ In this study, $91 \%$ of children with moderate-severe AD were sensitized to at least one of the five most common food allergens, and 51\% reported acute clinical reactivity to at least one of these foods. Specific IgE levels, particularly to milk, egg, and peanut, were significantly higher in subjects allergic versus tolerant to these foods, and IgE thresholds could be identified that effectively discriminated allergic status. Although ratios of specific to total $\operatorname{IgE}$ were not better at predicting allergy than SIgE values alone, component IgE testing had additional utility.

$\mathrm{AD}$ patients are known to be more likely to exhibit false positive testing for food allergy. In a study of infants with mild-moderate AD, $15.9 \%$ developed at least one food allergy over a 6-year period. Although baseline sIgE levels were significantly higher among infants who developed food allergy compared to those who didn't, the authors were unable to identify a threshold of sIgE that distinguished these groups. In contrast, we identified $\operatorname{sIgE}$ decision points for milk, egg, and peanut with high sensitivity, specificity and predictive value that distinguished allergic status. Importantly, there were no significant differences in eczema severity in those with and without allergy. One possible explanation for this discrepancy may be related to the difference in age between the cohorts studied. The prior study enrolled 
infants less than one year of age (median age 7.3 months), while the median age in our study was 10.7 years. Although a study from National Jewish Health that enrolled older children (median age 4 years) found that most AD patients avoiding foods due to positive testing had negative OFCs, participants whose sIgE values exceeded the 95\% PPV values for milk, egg, and peanut were not challenged. ${ }^{15}$ Our results suggest that the sIgE values that strongly predict allergy in patients with moderate-severe $\mathrm{AD}$ are well above the commonly used values of $32 \mathrm{kU}_{\mathrm{A}} / \mathrm{L}$ for milk, $7 \mathrm{kU} \mathrm{A}_{\mathrm{A}} / \mathrm{L}$ for egg, and $15 \mathrm{kU}_{\mathrm{A}} / \mathrm{L}$ for peanut. ${ }^{16-19}$ Indeed, we estimated that $\mathrm{AD}$ subjects with a milk IgE of $43 \mathrm{kU} / \mathrm{A}$, egg $\operatorname{IgE}$ of $28 \mathrm{kU}_{\mathrm{A}} / \mathrm{L}$ and peanut IgE of $34 \mathrm{kU}_{\mathrm{A}} / \mathrm{L}$ had at least a $50 \%$ chance of not being allergic to the food. Therefore, we propose that sIgE testing may have utility in predicting food allergy in patients with moderate-severe $\mathrm{AD}$ and high total serum IgE levels, although the decision points may be much higher than those that apply to a less atopic population. Of note, subjects in our study were selected with no bias for the presence or absence of food allergy.

Component testing is emerging as a promising approach that can improve the accuracy of food allergy diagnosis, particularly for peanut allergy where Ara $\mathrm{h} 2$ is a strong predictor of disease. ${ }^{23-28}$ High IgE levels to Gal d1 (ovomucoid) and Bos d8 (casein) have also been associated with more persistent allergy as well as reactivity to both heated and concentrated forms of egg and milk, respectively. ${ }^{29-38} \mathrm{We}$ found that a significantly greater proportion of IgE to peanut in allergic subjects was directed against Ara h2 and Ara h1, both of which have been associated with severe reactions. ${ }^{24,25,41,42}$ In contrast, peanut IgE in nonallergic subjects was primarily specific for Ara h8, which is homologous to the birch pollen allergen Bet v1 and has been associated with no or only mild local symptoms. ${ }^{43}, 44$ Likewise, the majority of milk IgE was directed against Bos $\mathrm{d} 8$ in allergic children and against the heatlabile components Bos d4 (alpha-lactoglobulin) and Bos d5 (beta-lactoglobulin), as well as Bos d6 (bovine serum albumin) in those without milk allergy. Subjects with egg allergy tended to have a greater fraction of their egg IgE directed against Gal d1, while Gal d3 IgE predominated in those subjects who were tolerant to egg. The presence of egg allergy also appeared to be a strongly associated with the development of other food allergies, as has been observed in prior studies. ${ }^{45,46}$

Consistent with prior studies of infants with $\mathrm{AD}$, wheat and soy allergy were relatively rare in this cohort of patients with moderate-severe AD. ${ }^{11}$ Despite this limitation, wheat and Tri a19 IgE levels, which has previously been associated with IgE-mediated wheat allergy, were higher among those with wheat allergy. ${ }^{47,}{ }^{48}$ However, neither soy IgE nor IgE to any of the soy components were significantly different between subjects with and without soy allergy, although this is perhaps in part due to the low number of patients with this allergy.

Given the high total serum IgE levels in this patient cohort, we hypothesized that the ratio of specific to total IgE may be better than sIgE levels alone in predicting food allergy. However, our data revealed a positive association between both of these parameters and allergy to all foods studied (with the exception of soy), and the ratio of specific to total $\operatorname{IgE}$ did not provide added information that would further inform clinical decision making.

Our study has several important limitations. First, the diagnosis of food allergy was not confirmed by OFC. However, the vast majority of allergic patients had sIgE levels well 
above the 95\% PPVs commonly used in the United States, which raised ethical concerns about the safety of challenging these patients under current guidelines. Subjects whose allergic status was not clear because they had never eaten the food (avoiding it due to positive testing) were excluded from the analysis for that food, which may have skewed our results, particularly for peanut. The size of our cohort was relatively small, and while we were able to identify highly significant differences between those subjects with and without milk, egg, and peanut allergy, we had less power for wheat and soy.

Many children with $\mathrm{AD}$ are on overly restrictive diets that exclude foods they have either never eaten or once tolerated but now avoid due to positive sIgE testing. The care of these patients would be dramatically improved if decision points for specific or component IgEs could be identified that predict when a true food allergy is present. In contrast to prior studies in infants, this study in school-aged children suggests that sIgE testing for the common food allergens may be helpful in guiding OFCs in this difficult-to-diagnose population, and that component testing may have additional diagnostic value. Although additional studies that incorporate OFCs to confirm the diagnosis of food allergy are needed to identify more definitive threshold levels, our data suggest that practitioners should likely be more aggressive about offering OFCs in patients with moderate-severe AD and elevated total IgE levels.

\section{Supplementary Material}

Refer to Web version on PubMed Central for supplementary material.

\section{Funding Source}

This research was supported by the Intramural Research Program of the National Institute of Allergy and Infectious Diseases, NIH. This project was funded in part with federal funds from NCI, NIH under Contract No.

HHSN26120080000IE (to W.G). The content of this publication does not necessarily reflect the views or policies of the Department of Health and Human Services, nor does mention of trade names, commercial products, or organizations imply endorsement by the U.S. Government.

\section{Abbreviations}

$\begin{array}{ll}\text { AD } & \text { atopic dermatitis } \\ \text { SIgE } & \text { food-specific IgE } \\ \text { OFC } & \text { oral food challenge } \\ \text { PPV } & \text { positive predictive value } \\ \text { SCORAD } & \text { severity of atopic dermatitis index score } \\ \text { MW } & \text { Mann-Whitney estimate } \\ \text { NPV } & \text { negative predictive value } \\ \text { CI } & \text { confidence interval } \\ \text { AUC } & \text { area under the curve }\end{array}$




\section{References}

1. Hanifin JM, Reed ML, Eczema P, Impact Working G. A population-based survey of eczema prevalence in the United States. Dermatitis : Contact, Atopic, Occupational, Drug. 2007;18:82-91.

2. Flohr C, Mann J. New insights into the epidemiology of childhood atopic dermatitis. Allergy. 2014;69:3-16. [PubMed: 24417229]

3. Worldwide variation in prevalence of symptoms of asthma, allergic rhinoconjunctivitis, and atopic eczema: ISAAC. The International Study of Asthma and Allergies in Childhood (ISAAC) Steering Committee. Lancet. 1998;351:1225-1232. [PubMed: 9643741]

4. Roduit C, Frei R, Loss G, et al. Development of atopic dermatitis according to age of onset and association with early-life exposures. The Journal of Allergy and Clinical Immunology. 2012;130:130-136 e135. [PubMed: 22521248]

5. Tsakok T, Marrs T, Mohsin M, et al. Does atopic dermatitis cause food allergy? A systematic review. The Journal of Allergy and Clinical Immunology. 2016; 137: 1071-1078. [PubMed: 26897122]

6. Martin PE, Eckert JK, Koplin JJ, et al. Which infants with eczema are at risk of food allergy? Results from a population-based cohort. Clinical and Experimental Allergy. 2015;45:255-264. [PubMed: 25210971]

7. Hill DJ, Hosking CS, de Benedictis FM, et al. Confirmation of the association between high levels of immunoglobulin $\mathrm{E}$ food sensitization and eczema in infancy: an international study. Clinical and Experimental Allergy. 2008;38:161-168. [PubMed: 18028467]

8. de Benedictis FM, Franceschini F, Hill D, et al. The allergic sensitization in infants with atopic eczema from different countries. Allergy. 2009;64:295-303. [PubMed: 19133917]

9. Burks AW, James JM, Hiegel A, et al. Atopic dermatitis and food hypersensitivity reactions. The Journal of Pediatrics. 1998;132:132-136. [PubMed: 9470014]

10. Gray CL, Levin ME, Zar HJ, et al. Food allergy in South African children with atopic dermatitis. Pediatric Allergy and Immunology. 2014;25:572-579. [PubMed: 25201137]

11. Spergel JM, Boguniewicz M, Schneider L, Hanifin JM, Paller AS, Eichenfield LF. Food Allergy in Infants With Atopic Dermatitis: Limitations of Food-Specific IgE Measurements. Pediatrics. 2015;136:e1530-1538. [PubMed: 26598458]

12. Flohr C, Perkin M, Logan K, et al. Atopic dermatitis and disease severity are the main risk factors for food sensitization in exclusively breastfed infants. The Journal of Investigative Dermatology 2014;134:345-350. [PubMed: 23867897]

13. Venkataraman D, Soto-Ramirez N, Kurukulaaratchy RJ, et al. Filaggrin loss-of-function mutations are associated with food allergy in childhood and adolescence. The Journal of Allergy and Clinical Immunology 2014;134:876-882 e874. [PubMed: 25174864]

14. Du Toit G, Roberts G, Sayre PH, et al. Randomized trial of peanut consumption in infants at risk for peanut allergy. The New England Journal of Medicine. 2015;372:803-813. [PubMed: 25705822]

15. Fleischer DM, Bock SA, Spears GC, et al. Oral food challenges in children with a diagnosis of food allergy. The Journal of Pediatrics. 2011;158:578-583 e571. [PubMed: 21030035]

16. Santos AF, Brough HA. Making the Most of In Vitro Tests to Diagnose Food Allergy. The Journal of Allergy and Clinical Immunology In Practice. 2017;5:237-248. [PubMed: 28283150]

17. Sampson HA. Utility of food-specific IgE concentrations in predicting symptomatic food allergy. The Journal of Allergy and Clinical Immunology. 2001;107:891-896. [PubMed: 11344358]

18. Sicherer SH, Morrow EH, Sampson HA. Dose-response in double-blind, placebo-controlled oral food challenges in children with atopic dermatitis. The Journal of Allergy and Clinical Immunology. 2000;105:582-586. [PubMed: 10719311]

19. Perry TT, Matsui EC, Conover-Walker MK, Wood RA. Risk of oral food challenges. The Journal of Allergy and Clinical Immunology. 2004;114:1164-1168. [PubMed: 15536426]

20. Federly TJ, Jones BL, Dai H, Dinakar C. Interpretation of food specific immunoglobulin E levels in the context of total IgE. Annals of Allergy, Asthma \& Immunology. 2013;111:20-24. 
21. Grabenhenrich L, Lange L, Hartl M, et al. The component-specific to total IgE ratios do not improve peanut and hazelnut allergy diagnoses. The Journal of Allergy and Clinical Immunology. 2016;137:1751-1760 e1758. [PubMed: 27087317]

22. Gupta RS, Lau CH, Hamilton RG, Donnell A, Newhall KK. Predicting outcomes of oral food challenges by using the allergen-specific IgE-total IgE ratio. The Journal of Allergy and Clinical Immunology In Practice. 2014;2:300-305. [PubMed: 24811021]

23. Klemans RJ, Otte D, Knol M, et al. The diagnostic value of specific IgE to Ara h 2 to predict peanut allergy in children is comparable to a validated and updated diagnostic prediction model. The Journal of Allergy and Clinical Immunology. 2013;131:157-163. [PubMed: 23026497]

24. Lieberman JA, Glaumann S, Batelson S, Borres MP, Sampson HA, Nilsson C. The utility of peanut components in the diagnosis of IgE-mediated peanut allergy among distinct populations. The Journal of Allergy and Clinical Immunology In Practice. 2013;1:75-82. [PubMed: 24229825]

25. Dang TD, Tang M, Choo S, et al. Increasing the accuracy of peanut allergy diagnosis by using Ara h 2. The Journal of Allergy and Clinical Immunology. 2012;129:1056-1063. [PubMed: 22385632]

26. Santos AF, Douiri A, Becares N, et al. Basophil activation test discriminates between allergy and tolerance in peanut-sensitized children. The Journal of Allergy and Clinical Immunology. 2014;134:645-652. [PubMed: 25065721]

27. Nicolaou N, Poorafshar M, Murray C, et al. Allergy or tolerance in children sensitized to peanut: prevalence and differentiation using component-resolved diagnostics. The Journal of Allergy and Clinical Immunology. 2010;125:191-197 e191-113. [PubMed: 20109746]

28. Beyer K, Grabenhenrich L, Hartl M, et al. Predictive values of component-specific IgE for the outcome of peanut and hazelnut food challenges in children. Allergy. 2015;70:90-98. [PubMed: 25308885]

29. Ito K, Futamura M, Moverare R, et al. The usefulness of casein-specific IgE and IgG4 antibodies in cow's milk allergic children. Clinical and Molecular Allergy : CMA. 2012;10:1. [PubMed: 22212305]

30. D’Urbano LE, Pellegrino K, Artesani MC, et al. Performance of a component-based allergenmicroarray in the diagnosis of cow's milk and hen's egg allergy. Clinical and Experimental Allergy. 2010;40: 1561-1570. [PubMed: 20633029]

31. Ohtani K, Sato S, Syukuya A, et al. Natural history of immediate-type hen's egg allergy in Japanese children. Allergology International. 2016;65:153-157. [PubMed: 26666473]

32. Ando H, Moverare R, Kondo Y, et al. Utility of ovomucoid-specific IgE concentrations in predicting symptomatic egg allergy. The Journal of Allergy and Clinical Immunology. 2008;122:583-588. [PubMed: 18692888]

33. Benhamou Senouf AH, Borres MP, Eigenmann PA. Native and denatured egg white protein IgE tests discriminate hen's egg allergic from egg-tolerant children. Pediatric Allergy and Immunology. 2015;26:12-17. [PubMed: 25443975]

34. Boyano-Martinez T, Garcia-Ara C, Pedrosa M, Diaz-Pena JM, Quirce S. Accidental allergic reactions in children allergic to cow's milk proteins. The Journal of Allergy and Clinical Immunology. 2009;123:883-888. [PubMed: 19232704]

35. Ahrens B, Lopes de Oliveira LC, Grabenhenrich L, et al. Individual cow's milk allergens as prognostic markers for tolerance development? Clinical and Experimental Allergy. 2012;42:1630 1637. [PubMed: 23106663]

36. Caubet JC, Nowak-Wegrzyn A, Moshier E, Godbold J, Wang J, Sampson HA. Utility of caseinspecific IgE levels in predicting reactivity to baked milk. The Journal of Allergy and Clinical Immunology. 2013;131:222-224 e221-224. [PubMed: 22921870]

37. Bernhisel-Broadbent J, Dintzis HM, Dintzis RZ, Sampson HA. Allergenicity and antigenicity of chicken egg ovomucoid (Gal d III) compared with ovalbumin (Gal d I) in children with egg allergy and in mice. The Journal of Allergy and Clinical Immunology. 1994;93:1047-1059. [PubMed: 8006309]

38. Sicherer SH, Wood RA, Vickery BP, et al. The natural history of egg allergy in an observational cohort. The Journal of Allergy and Clinical Immunology. 2014;133:492-499. [PubMed: 24636473] 
39. Sampson HA, Gerth van Wijk R, Bindslev-Jensen C, et al. Standardizing double-blind, placebocontrolled oral food challenges: American Academy of Allergy, Asthma \& Immunology-European Academy of Allergy and Clinical Immunology PRACTALL consensus report. The Journal of Allergy and Clinical Immunology. 2012;130:1260-1274. [PubMed: 23195525]

40. James G, Witten D, Hastie T, Tibshirani R. An introduction to statistical learning : with applications in R. New York: Springer; 2013.

41. Klemans RJ, van Os-Medendorp H, Blankestijn M, Bruijnzeel-Koomen CA, Knol EF, Knulst AC. Diagnostic accuracy of specific IgE to components in diagnosing peanut allergy: a systematic review. Clinical and Experimental Allergy. 2015;45:720-730. [PubMed: 25226880]

42. Klemans RJ, Broekman HC, Knol EF, et al. Ara h 2 is the best predictor for peanut allergy in adults. The Journal of Allergy and Clinical Immunology In Practice. 2013;1:632-638 e631. [PubMed: 24565711]

43. Sicherer SH, Wood RA. Advances in diagnosing peanut allergy. The Journal of Allergy and Clinical Immunology In Practice. 2013;1:1-13; quiz 14. [PubMed: 24229816]

44. Asarnoj A, Nilsson C, Lidholm J, et al. Peanut component Ara h 8 sensitization and tolerance to peanut. The Journal of Allergy and Clinical Immunology. 2012;130:468-472. [PubMed: 22738678]

45. Sampson HA. Clinical practice. Peanut allergy. The New England Journal of Medicine. 2002;346:1294-1299. [PubMed: 11973367]

46. Du Toit G, Roberts G, Sayre PH, et al. Identifying infants at high risk of peanut allergy: the Learning Early About Peanut Allergy (LEAP) screening study. The Journal of Allergy and Clinical Immunology 2013;131:135-143 e131-112. [PubMed: 23174658]

47. Nilsson N, Sjolander S, Baar A, et al. Wheat allergy in children evaluated with challenge and IgE antibodies to wheat components. Pediatric Allergy and Immunology. 2015;26:119-125. [PubMed: 25601168]

48. Ebisawa M, Shibata R, Sato S, Borres MP, Ito K. Clinical utility of IgE antibodies to omega-5 gliadin in the diagnosis of wheat allergy: a pediatric multicenter challenge study. Int Arch Allergy Immunol. 2012;158:71-76. [PubMed: 22212744] 

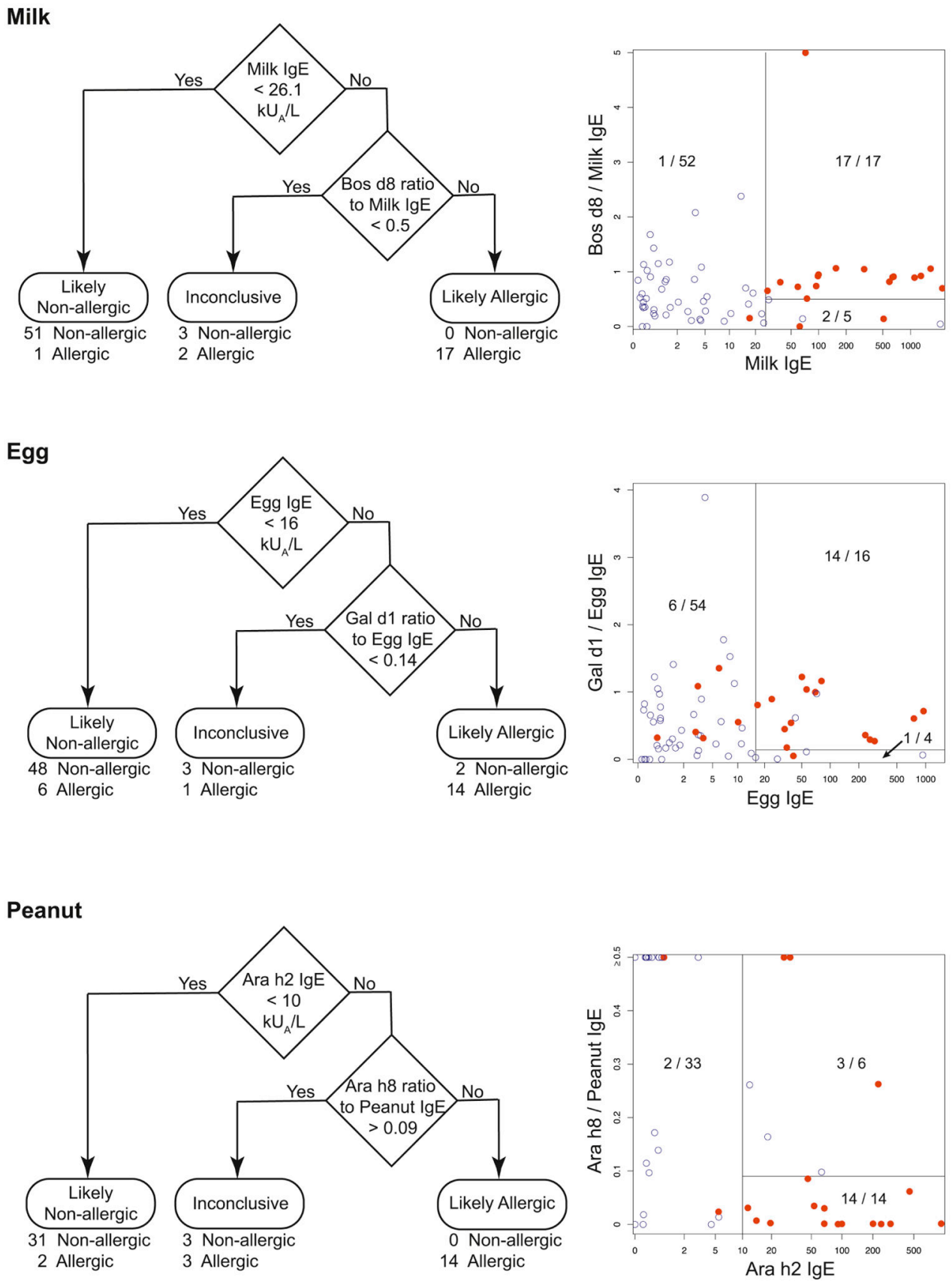

Fig 1.

Decision trees and corresponding scatterplots for predicting milk, egg, and peanut allergy based on food specific- and component-IgE levels. 
Table 1.

Characteristics of study participants overall, those allergic to at least one of the five most common food allergens, and those with no known allergies to any of the five foods

\begin{tabular}{|c|c|c|c|}
\hline & Overall & Allergic & Nonallergic \\
\hline $\mathrm{N}$ & 78 & 40 & 38 \\
\hline Male N (\%) & $51(65 \%)$ & $28(70 \%)$ & $23(61 \%)$ \\
\hline Age (years) ${ }^{*}$ & $10.7(7.9-14.4)$ & $10.5(5.7-14.6)$ & $10.7(8.2-14.3)$ \\
\hline SCORAD* & $45(31-56)$ & $42(31-60)$ & $46(34-53)$ \\
\hline Total IgE (kU/L) ${ }^{*}$ & $5338(1938-14416)$ & $8430(3946-19095)^{t^{t}}$ & $3323(1076-9140)^{*}$ \\
\hline Asthma N (\%) & $55(71 \%)$ & $40(75 \%)$ & $25(66 \%)$ \\
\hline AR N $(\%)$ & $71(91 \%)$ & $37(93 \%)$ & $34(89 \%)$ \\
\hline $\operatorname{EoE~N}(\%)$ & $3(4 \%)$ & $3(8 \%)$ & $0(0 \%)$ \\
\hline Ethnicity (Hispanic) N (\%) & $3(4 \%)$ & $1(3 \%)$ & $2(5 \%)$ \\
\hline \multicolumn{4}{|l|}{ Race N (\%) } \\
\hline Caucasian & $34(44 \%)$ & $20(50 \%)$ & $14(37 \%)$ \\
\hline Asian & $19(24 \%)$ & $10(25 \%)$ & $9(24 \%)$ \\
\hline African American & $10(13 \%)$ & $3(8 \%)$ & $7(18 \%)$ \\
\hline Multiracial & $11(14 \%)$ & $7(18 \%)$ & $4(11 \%)$ \\
\hline American Indian / Alaska Native & $1(1 \%)$ & $0(0 \%)$ & $1(3 \%)$ \\
\hline Indian & $1(1 \%)$ & $0(0 \%)$ & $1(3 \%)$ \\
\hline Unknown & $2(2 \%)$ & $0(0 \%)$ & $2(6 \%)$ \\
\hline \multicolumn{4}{|l|}{ median $\left(25^{\text {th }}-75^{\text {th }}\right.$ percentile $)$} \\
\hline \multicolumn{4}{|c|}{ Total IgE significantly different between Allergic and Nonallergic groups; $\mathrm{p}=0.0165$} \\
\hline \multicolumn{4}{|l|}{ AR: Allergic Rhinitis } \\
\hline EoE: Eosinophilic Esophagitis & & & \\
\hline
\end{tabular}


Table 2.

Milk: Median $\left(25^{\text {th }}-75^{\text {th }}\right.$ percentile) and Mann-Whitney parameter (95\% confidence interval) for SCORAD and levels of total, milk-specific, and milk component $\operatorname{IgE}$ and their ratios in subjects allergic or nonallergic to milk

\begin{tabular}{cccccc} 
& & $\begin{array}{c}\text { Non-Allergic } \\
\text { (N=54) }\end{array}$ & $\begin{array}{c}\text { Allergic } \\
(\mathbf{N = 2 0})\end{array}$ & Mann-Whitney & $\begin{array}{c}\text { Wilcoxon Test } \\
\text { p-value }\end{array}$ \\
\hline & SCORAD & $47(34-57)$ & $42(31-57)$ & $0.46(0.32-0.61)$ & 0.6090 \\
& Total IgE & $4816(1474-14012)$ & $8430(4052-19204)$ & $0.60(0.45-0.73)$ & 0.1907 \\
& Milk IgE & $1.1(0.3-4.7)$ & $127.5(69.7-642)$ & $0.97(0.88-0.99)$ & $<0.00001$ \\
& Bos d4 & $0.4(0.1-1.4)$ & $42.8(14.1-74.1)$ & $0.92(0.80-0.97)$ & $<0.00001$ \\
& Bos d5 & $0.5(0.2-1.4)$ & $45.9(6.2-66.7)$ & $0.90(0.78-0.95)$ & $<0.00001$ \\
& Bos d6 & $0.3(0.1-2.6)$ & $1.4(0.3-29.4)$ & $0.70(0.55-0.81)$ & 0.0104 \\
& Bos d8 & $0.6(0.1-2.1)$ & $130(41.9-581)$ & $0.94(0.83-0.98)$ & $<0.00001$ \\
& Milk IgE & $2.10(0.75-6.54)$ & $351.63(168.96-573.75)$ & $0.96(0.87-0.99)$ & $<0.00001$ \\
& Bos d4 & $0.57(0.23-1.52)$ & $48.80(27.56-112.10)$ & $0.92(0.81-0.97)$ & $<0.00001$ \\
Ratio to Total IgE $(x$ 104) & Bos d5 & $0.77(0.31-2.04)$ & $41.84(19.79-112.39)$ & $0.89(0.77-0.95)$ & $<0.00001$ \\
& Bos d6 & $0.71(0.25-1.97)$ & $3.99(0.33-19.83)$ & $0.67(0.52-0.79)$ & 0.0252 \\
& Bos d8 & $0.69(0.35-3.57)$ & $318.98(111.03-427.98)$ & $0.94(0.83-0.98)$ & $<0.00001$ \\
& Bos d4 & $0.434(0.113-0.624)$ & $0.175(0.096-0.398)$ & $0.36(0.24-0.51)$ & 0.0726 \\
& Bos d5 & $0.602(0.215-0.795)$ & $0.114(0.066-0.369)$ & $0.25(0.14-0.39)$ & 0.0011 \\
& Bos d6 & $0.602(0.115-0.970)$ & $0.007(0.000-0.128)$ & $0.25(0.15-0.40)$ & 0.0012 \\
Bos d8 & $0.448(0.236-0.853)$ & $0.856(0.688-0.931)$ & $0.67(0.52-0.79)$ & 0.0289 \\
\hline
\end{tabular}

Total IgE measurements are kU/L; milk-specific and component IgE measurements are $\mathrm{kU}_{\mathrm{A}} / \mathrm{L}$ 
Table 3.

Egg: Median $\left(25^{\text {th }}-75^{\text {th }}\right.$ percentile) and Mann-Whitney parameter (95\% confidence interval) for SCORAD and levels of total, egg-specific, and egg component $\mathrm{IgE}$ and their ratios in subjects allergic or nonallergic to egg

\begin{tabular}{cccccc} 
& & $\begin{array}{c}\text { Non-Allergic } \\
(\mathbf{N = 5 3})\end{array}$ & $\begin{array}{c}\text { Allergic } \\
(\mathbf{N = 2 1})\end{array}$ & Mann-Whitney & Wilcoxon Test p-value \\
\hline \multirow{6}{*}{ SCORAD } & $47(36-56)$ & $35(29-57)$ & $0.43(0.30-0.58)$ & 0.3747 \\
& Total IgE & $4857(1960-13637)$ & $6160(1930-17284)$ & $0.54(0.40-0.68)$ & 0.5731 \\
& Egg IgE & $1.3(0.4-6.4)$ & $38.5(10.1-81.1)$ & $0.86(0.74-0.93)$ & $<0.00001$ \\
& Gal d1 & $0.4(0.1-1.9)$ & $20.9(5.6-76.9)$ & $0.88(0.76-0.94)$ & $<0.00001$ \\
& Gal d2 & $0.5(0.2-3.1)$ & $31.3(3.7-62.4)$ & $0.86(0.74-0.93)$ & $<0.00001$ \\
& Gal d3 & $0.2(<0.1-0.6)$ & $0.6(0.2-7.7)$ & $0.63(0.48-0.75)$ & 0.0812 \\
& Egg IgE & $2.15(0.69-12.20)$ & $35.09(20.22-322.55)$ & $0.89(0.77-0.95)$ & $<0.00001$ \\
& Gal d1 & $0.48(0.13-2.66)$ & $26.15(13.68-124.84)$ & $0.90(0.79-0.96)$ & $<0.00001$ \\
& Gal d2 & $0.98(0.32-3.19)$ & $31.95(11.35-150.65)$ & $0.91(0.79-0.96)$ & $<0.00001$ \\
& Gal d3 & $0.26(0.00-0.89)$ & $0.73(0.29-8.74)$ & $0.66(0.51-0.78)$ & 0.0351 \\
& Gal d1 & $0.359(0.118-0.767)$ & $0.553(0.322-0.999)$ & $0.63(0.48-0.76)$ & 0.0872 \\
& Gal d2 & $0.687(0.278-0.974)$ & $0.730(0.380-0.956)$ & $0.54(0.39-0.68)$ & 0.6218 \\
& Gal d3 & $0.210(0.020-0.483)$ & $0.053(0.001-0.158)$ & $0.35(0.23-0.50)$ & 0.0500 \\
\hline
\end{tabular}

Total IgE measurements are kU/L; egg-specific and component IgE measurements are $\mathrm{kU} / \mathrm{L}$ 
Table 4.

Peanut: Median $\left(25^{\text {th }}-75^{\text {th }}\right.$ percentile) and Mann-Whitney parameter (95\% confidence interval) for SCORAD and levels of total, peanut (PN)-specific, and peanut component IgE and their ratios in subjects allergic or nonallergic to peanut

\begin{tabular}{cccccc} 
& & $\begin{array}{c}\text { Non-Allergic } \\
(\mathbf{N = 3 4})\end{array}$ & $\begin{array}{c}\text { Allergic } \\
(\mathbf{N = 1 9})\end{array}$ & Mann-Whitney & $\begin{array}{c}\text { Wilcoxon Test } \\
\text { p-value }\end{array}$ \\
\hline & SCORAD & $47(35-54)$ & $43(30-61)$ & $0.50(0.35-0.66)$ & 0.9778 \\
& Total IgE & $3467(564-9046)$ & $9082(4440-15077)$ & $0.69(0.53-0.81)$ & 0.0242 \\
& PN IgE & $4.5(0.4-17.8)$ & $91.9(49.1-469)$ & $0.92(0.79-0.97)$ & $<0.00001$ \\
& Ara hl & $0.1(<0.1-0.3)$ & $10.1(2.4-55.7)$ & $0.90(0.76-0.95)$ & $<0.00001$ \\
& Ara h2 & $0.3(<0.1-0.7)$ & $67.1(23.1-213.5)$ & $0.97(0.86-0.99)$ & $<0.00001$ \\
& Ara h3 & $0.2(<0.1-0.5)$ & $6.2(0.6-19.4)$ & $0.89(0.75-0.95)$ & $<0.00001$ \\
& Ara h8 & $0.4(<0.1-15.7)$ & $0.8(0.3-14.6)$ & $0.61(0.45-0.75)$ & 0.1785 \\
& Ara h9 & $0.2(<0.1-1.6)$ & $0.9(0.4-2.1)$ & $0.66(0.50-0.79)$ & 0.0499 \\
& PN IgE & $6.07(0.25-17.33)$ & $158.13(23.81-574.77)$ & $0.90(0.76-0.96)$ & $<0.00001$ \\
& Ara h1 & $0.12(0.00-0.51)$ & $15.51(1.79-62.59)$ & $0.88(0.75-0.95)$ & $<0.00001$ \\
Ara h2 & $0.26(0.00-1.19)$ & $111.65(15.03-216.22)$ & $0.95(0.83-0.98)$ & $<0.00001$ \\
Ara h3 & $0.18(0.00-0.54)$ & $4.73(1.28-23.37)$ & $0.90(0.77-0.96)$ & $<0.00001$ \\
& Ara h8 & $0.81(0.00-20.81)$ & $0.81(0.43-10.93)$ & $0.59(0.42-0.73)$ & 0.3085 \\
& Ara h9 & $0.31(0.00-1.75)$ & $0.78(0.35-2.70)$ & $0.65(0.49-0.78)$ & 0.0702 \\
Ara hl & $0.027(0.000-0.111)$ & $0.098(0.019-0.227)$ & $0.696(0.52-0.82)$ & 0.0279 \\
Ara h2 & $0.079(0.023-0.243)$ & $0.553(0.361-0.729)$ & $0.864(0.71-0.94)$ & 0.00004 \\
Ara h3 & $0.028(0.005-0.061)$ & $0.033(0.014-0.076)$ & $0.583(0.41-0.73)$ & 0.3549 \\
Ara h8 & $0.261(0.097-3.521)$ & $0.024(0.001-0.074)$ & $0.299(0.17-0.47)$ & 0.0243 \\
Ara h9 & $0.060(0.006-0.414)$ & $0.008(0.001-0.048)$ & $0.353(0.21-0.53)$ & 0.0992 \\
\hline
\end{tabular}

Total $\mathrm{gE}$ measurements are kU/L; peanut-specific and component IgE measurements are $\mathrm{kU} / \mathrm{L}$ 
Table 5.

Milk: Sensitivity, specificity, positive (PPV) and negative (NPV) predictive value for the milk-specific IgE level $(\mathrm{kU} / \mathrm{L})$ where the probability of being allergic is $50 \%$ (based on logistic model; $95 \%$ confidence interval), milk-IgE level $\geq 100 \mathrm{kU} / \mathrm{L}$, and the milk-IgE level that maximizes the sum of sensitivity and specificity

\begin{tabular}{llll}
\hline Milk & $\begin{array}{l}\text { Threshold: 50\% from } \\
\text { Logistic Model }\end{array}$ & Threshold: Milk-IgE $\geq \mathbf{1 0 0}$ & $\begin{array}{l}\text { Threshold: Sensitivity } \\
\text { Maximum of + Specificity }\end{array}$ \\
\hline IgE & $42.8(23.2-116.7){ }^{*}$ & 100 & 27.4 \\
Sensitivity & 0.850 & 0.550 & 0.950 \\
Specificity & 0.963 & 0.982 & 0.944 \\
PPV $^{*}$ & 0.835 & 0.917 & 0.864 \\
NPV $^{*}$ & 0.932 & 0.855 & 0.981 \\
\hline
\end{tabular}

from Logistic Model, Bootstrap-based 95\% CI

Model based PPV and NPV 
Table 6.

Egg: Sensitivity, specificity, positive (PPV) and negative (NPV) predictive value for the egg-specific IgE level $(\mathrm{kU} / \mathrm{L})$ where the probability of being allergic is $50 \%$ (based on logistic model; $95 \%$ confidence interval), eggIgE level $\geq 100 \mathrm{kU} / \mathrm{L}$, and the egg-IgE level that maximizes the sum of sensitivity and specificity

\begin{tabular}{cccc}
\hline Egg & $\begin{array}{c}\text { Threshold: 50\% from } \\
\text { Logistic Model }\end{array}$ & $\begin{array}{c}\text { Threshold: } \\
\text { Egg-IgE } \geq \mathbf{1 0 0}\end{array}$ & $\begin{array}{c}\text { Threshold: Maximum } \\
\text { of Sensitivity + } \\
\text { Specificity }\end{array}$ \\
\hline IgE & $28.0(11.4-103.8) \neq$ & 100 & 16.7 \\
Sensitivity & 0.619 & 0.238 & 0.714 \\
Specificity & 0.905 & 0.981 & 0.906 \\
PPV $^{*}$ & 0.709 & 0.833 & 0.750 \\
NPV $^{*}$ & 0.847 & 0.765 & 0.889 \\
\hline \multirow{4}{*}{ from Logistic Model, Bootstrap-based 95\% CI } \\
* \\
Model based PPV and NPV
\end{tabular}


Table 7.

Peanut: Sensitivity, specificity, positive (PPV) and negative (NPV) predictive value for the peanut- or Ara h2specific IgE level (kU/L) where the probability of being allergic is 50\% (based on logistic model; $95 \%$ confidence interval), peanut- or Ara h2-IgE level $\geq 100 \mathrm{kU} / \mathrm{L}$, and the peanut- or Ara h2-IgE level that maximizes the sum of sensitivity and specificity

\begin{tabular}{|c|c|c|c|c|}
\hline & & $\begin{array}{l}\text { Threshold: } \mathbf{5 0 \%} \\
\text { from Logistic } \\
\text { Model }\end{array}$ & $\begin{array}{l}\text { Threshold: } \\
\text { Peanut- or Ara h2- } \\
\text { IgE } \geq 100\end{array}$ & $\begin{array}{l}\text { Threshold: Maximum of } \\
\text { Sensitivity + Specificity }\end{array}$ \\
\hline \multirow[t]{5}{*}{ Peanut } & $\operatorname{IgE}$ & $36.4(19.8-66.7) t$ & 100 & 35.600 \\
\hline & Sensitivity & 0.737 & 0.421 & 0.790 \\
\hline & Specificity & 0.941 & 1 & 0.941 \\
\hline & $\mathrm{PPV}^{*}$ & 0.830 & 1 & 0.882 \\
\hline & $\mathrm{NPV}^{*}$ & 0.846 & 0.756 & 0.889 \\
\hline \multirow[t]{5}{*}{ Ara h2 } & $\operatorname{IgE}$ & $10.9(4.6-24.5) \neq$ & 100 & 5.450 \\
\hline & Sensitivity & 0.895 & 0.316 & 0.947 \\
\hline & Specificity & 0.912 & 1 & 0.882 \\
\hline & $\mathrm{PPV}^{*}$ & 0.859 & 1 & 0.818 \\
\hline & $\mathrm{NPV}^{*}$ & 0.924 & 0.723 & 0.968 \\
\hline
\end{tabular}

